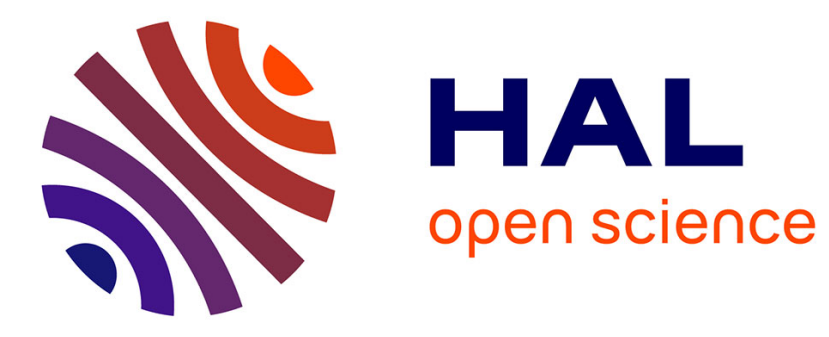

\title{
Value-chain wide food waste management: A systematic literature review
}

\author{
Guoqing Zhao, Shaofeng Liu, Huilan Chen, Carmen Lopez, Jorge Hernandez, \\ Cécile Guyon, Rina Iannacone, Nicola Calabrese, Hervé Panetto, Janusz
}

Kacprzyk, et al.

\section{To cite this version:}

Guoqing Zhao, Shaofeng Liu, Huilan Chen, Carmen Lopez, Jorge Hernandez, et al.. Value-chain wide food waste management: A systematic literature review. 5th International Conference on Decision Support System Technology, EmC-ICDSST 2019, May 2019, Funchal, Madeira, Portugal. pp.41-54, 10.1007/978-3-030-18819-1_4. hal-02157909

\section{HAL Id: hal-02157909 \\ https://hal.science/hal-02157909}

Submitted on 17 Jun 2019

HAL is a multi-disciplinary open access archive for the deposit and dissemination of scientific research documents, whether they are published or not. The documents may come from teaching and research institutions in France or abroad, or from public or private research centers.
L'archive ouverte pluridisciplinaire HAL, est destinée au dépôt et à la diffusion de documents scientifiques de niveau recherche, publiés ou non, émanant des établissements d'enseignement et de recherche français ou étrangers, des laboratoires publics ou privés. 


\title{
Value-chain wide food waste management: a systematic literature review
}

Guoqing Zhao ${ }^{1 *}$, Shaofeng Liu ${ }^{1}$, Huilan Chen ${ }^{1}$, Carmen Lopez ${ }^{2}$, Jorge Hernandez ${ }^{3}$, Cécile Guyon ${ }^{4}$, Rina Iannacone $^{5}$, Nicola Calabrese ${ }^{6}$, Hervé Panetto ${ }^{7}$, Janusz Kacprzyk ${ }^{8}$, Mareva Alemany ${ }^{9}$

${ }^{1}$ University of Plymouth United Kingdom, ${ }^{2}$ University of Brighton United Kingdom, ${ }^{3}$ University of Liverpool United Kingdom, ${ }^{4}$ Bretagne Développement Innovation France, ${ }^{5}$ ALSIA Italy, ${ }^{6}$ CNR-ISPA Italy

${ }^{7}$ University of Lorraine, CNRS, CRAN France, ${ }^{8}$ IBSPAN Poland, ${ }^{9}$ Universitat Politècnica de València Spain

\begin{abstract}
The agriculture value chain, from farm to fork, has received enormous attention because of its key role in achieving United Nations Global Challenges Goals. Food waste has become a worldwide issue that requires urgent actions. While there are still many people who do not have sufficient food on the table, managing foo ${ }^{1} \mathrm{~d}$ waste effectively should provide means to reduce starvation and improve health. Food waste occurs in many different forms and at all stages of the food value chain. However, the management of food waste has been traditionally segmented and in an isolated manner. This paper reviews existing work that has been done on food waste management in literature by taking a holistic approach, in order to identify the causes of food waste generation, food waste prevention strategies, and elicit recommendations for future work.

The methodology used for identifying the causes of food waste generation and food waste prevention strategies presented here is a systematic literature review. A five step review process has been adopted-for a thorough examination of the existing research on the topic and new insights have been obtained. The findings suggest that there are various sources of food waste existing in the current food value chain. The review reveals that the main sources of food waste include food overproduction and surplus, food waste caused by processing, food waste caused by logistical inconsistencies and food waste caused by household level. The review also exposes that main food waste prevention strategies include policy solutions, packaging solutions, date labelling solutions, logistics solutions, changing consumers' behaviours, and reuse and redistribution solutions. Future research directions such as using value chain models to reduce food waste and forecasting food waste have been identified in this paper. This study makes a contribution to the extant literature in the field of food waste management by discovering main causes of food waste in the value chain and eliciting prevention strategies that can be used to reduce/eliminate relevant food waste.
\end{abstract}

Keywords. Systematic literature review, food waste generation, cause of waste, food waste prevention strategies

\section{Introduction}

In 2011 the Food and Agriculture Organisation of the United Nations estimated that roughly one third of the worldwide food produced for human consumption is lost or wasted from the initial stage of production to the final stage of consumption, which amounts to about 1.3 billion tons per year [1]. According to the European Commission [2], food waste has been classified into three different categories: (1)

"food losses: food products lost during the production phase; (2) unavoidable food waste: referring to food products lost during the consumption phase (banana peels, fruit cores, etc); (3) avoidable food waste: products that could have been eaten, but were lost during consumption phase". Food losses typically but not exclusively happen at the production, postharvest and processing stage of the food value chain [3], whereas food waste always takes place at the final stage of food value chain such as during retail and consumption stage [4].

In order to reduce food waste in food value chains, food waste management has received great attention in recent years. [5] investigated the root causes of food waste from the retail and store operations perspective. Their findings indicate that undesirable customer behaviour and erratic demand, inefficient store operations and replenishment policies, and elevated product requirements of both retail organisations and customers are the root causes of food waste. [6] found that investigating the causes of food waste deepens the understanding in food waste and helps to design food waste prevention strategies.

In this study, in order to have a deep understanding on food waste in food value chains, we aim to address two key questions: (1) What are the main causes of food waste in food value chains? (2) What are the key food waste prevention strategies that can be used in food value chains? In order to answer the above questions, the remainder of this paper is organised as follows. The process of systematic literature review (SLR) is described in Section 2. Then, the thematic analysis about causes of food waste and the possible food waste prevention strategies are outlined in Section 3. In section 4, research gaps are identified from the SLR and future research directions are

*Corresponding author, zhaoguoqing9211@163.com 
proposed. Finally, conclusions and the main connections between food waste generation and food waste prevention strategies are discussed in Section 5.

\section{Research methodology: systematic literature review}

A systematic literature review (SLR) is an explicit and methodical way to gain a deep understanding on a given topic to inform academics and practitioners [7]. Unlike traditional narrative reviews, a SLR follows a set of strict guidelines to search for the most relevant literatures in a comprehensive and transparent way, and apply an evidence-based explanation with specific criteria of the body of previous literatures [8]. This paper follows the five phases of SLR methodology proposed by [7]: (1) Formulating the research questions; (2) Locating the study; (3) Study selection and evaluation; (4) Analysis and synthesis; (5) Reporting and using the results. This approach is systematic, reproducible and rigorous and used to identify, synthesize, interpret the best evidence from previous food waste management literatures.

\subsection{Formulating the research questions}

The first stage for conducting SLR is to formulate research questions, which should clearly focus on the food waste generation as well as the food waste prevention strategies used in food value chains. The research questions were formulated based on the following process: (1) Brainstorming all types of food waste in food value chains; (2) Consult with experts, academics in the agri-food industry, to identify root causes of food waste; (3) Examine possible strategies to reduce food waste.

\subsection{Locating study}

Two databases were selected for the literature search: Web of Science and Business Source Complete. These databases were selected as they include the global major journals and conference proceedings especially in social science [9]. In addition to the keywords, relevant literature was identified based on previous papers and books on the food waste management. Furthermore, consulting with practitioners and academics in the relevant field was used to confirm whether keywords were appropriate and also necessary [10]. The keywords were combined through Boolean connectors in order to constitute different search strings to be applied in the databases. Since the focus of our research is the source of food waste and food waste prevention, the strings were specially designed in order to select the most relevant papers, identifying overlaps between food waste generation and food waste prevention in general. Search strings partly include "food waste" AND "value chain", "food waste prevention strategies" AND "value chain". The strings were then used to search for titles and abstracts containing these terms among journals in the Web of Science and Business Source Complete. The electronic search process resulted in the identification of 788 articles from the Web of Science and 83 articles from Business Source complete.

\subsection{Study selection and evaluation}

In order to obtain and include the most relevant and important studies to concentrate on, a list of inclusion criteria should be defined. The following criteria in Table 1 based on the ones proposed by [6] have been considered to include/exclude papers. During the first screening, which included reading the title and abstract of each paper, in total 871 papers were screened at this stage. Papers that did not meet the inclusion criteria or were not relevant to the topic or were duplicates were excluded. The remaining 185 articles were prepared for the second screening. After reading the introduction and conclusion of the remained papers, 45 papers were excluded due to being either not relevant to the topic or a limitation to access. Through these two screening processes, 140 papers remained as potential candidates for full paper review process. A further 7 articles were identified through cross-referencing citation. Finally, 147 papers were prepared for full paper review process.

Table 1. Criteria for inclusion papers

Inclusion criteria $\quad$ Rationale




\begin{tabular}{|l|l|}
\hline $\begin{array}{l}\text { Published in peer-reviewed } \\
\text { journals }\end{array}$ & $\begin{array}{l}\text { Peer-reviewed journals are considered to be have better } \\
\text { quality than non-peer-reviewed articles }\end{array}$ \\
\hline $\begin{array}{l}\text { Selection of papers published } \\
\text { from 1980-2017 }\end{array}$ & $\begin{array}{l}\text { The year 1980 was selected as the starting point due to the } \\
\text { emergence of studies on food waste around this time }\end{array}$ \\
\hline Published in English language & $\begin{array}{l}\text { English is the dominant language in the field of food waste } \\
\text { management }\end{array}$ \\
\hline $\begin{array}{l}\text { Food waste addressed within the } \\
\text { context of value chain } \\
\text { management }\end{array}$ & $\begin{array}{l}\text { The aim of the review is to analysis food waste in food } \\
\text { value chains }\end{array}$ \\
\hline
\end{tabular}

\subsection{Analysis and synthesis}

The objective of this phase is to analyse and synthesise the selected 147 papers so as to develop new knowledge about the food waste generation and food waste prevention that were not visible through reading each of paper individually. Analysis was conducted through recording the summary of each of the papers into the spreadsheet of Microsoft Excel, while each paper was broken down into different features of food waste management. synthesis was achieved through building connection between the themes in each of the paper. Four different approaches such as aggregation, integration, interpretation, and explanation are used in the synthesis process [11].

\subsection{Reporting and using the results}

This stage of SLR provides the findings from the selected papers, the relationships between each other and the extent of what is known and what is not known about the research questions [7]. Furthermore, findings can help to generate new knowledge and provide recommendations for future research.

\section{Findings}

The findings of SLR are reported in two sections, each of which will deepen our understandings and elicit current trends on food waste management. First of all, the causes of food waste were analysed and categorized into different themes. Secondly, food waste prevention strategies and related managerial practices are examined.

\subsection{Thematic analysis: causes of food waste in the value chain}

In order to provide edible products for human consumption, food has to pass multiple stages along the value chain. It begins with raw material production, followed by handling and storage, and subsequently with processing and packing, and then distribution to markets, and finally distribution to consumers through retailing system [12]. After reviewing the literatures on the phenomenon of food waste, [5] concluded that food waste-related literature reflects an emphasis on describing the causes of food waste and its impact in selected geographic settings and across different stages of the food value chain. Although food is wasted at all stages of food value chain, four main areas of food waste generation were identified and discussed in previous literatures. They are food overproduction and surplus, food wasted during food processing, product deterioration and spoilage during logistics operations and food waste caused by households $[12,13]$.

Food overproduction and surplus. An important perspective of food waste generation is over-production. The need for over-production mainly stems from trade demands: the uncertainty to meet quality requirements and to be burdened by contractual penalties or product take-back obligations may cause a higher production volume [4]. Insufficient communication and reluctance to share information between food value chain members are the main reasons for poor forecasting [14]. After conducting various interviews with representatives from 13 German food processing companies, [12] revealed that producers rely on previous experience and past sales numbers to forecast production volume. Their research also indicates that in order to fulfil customers' requirements, over-production is tolerated to some extent especially for some fresh bakery products. In this way, consumers' anticipation of permanently full shelves helps to foster over-production, and retailers are forced to find the right balance between a maximum on-shelf-availability and a minimum of unsold food surplus [15]. After investigating 83 firms in the sector of food manufacturing and retailing, the primary source of surplus food is revealed. Five main reasons for the generation of surplus food in the food manufacturing industry are: products that have reached the internal sellby date, product non-compliance with commercial standards, non-compliance of product packing with required standards, product refusals and return of unsold products. Besides the surplus food generated in the food manufacturing industry, four main reasons for the generation of surplus food in the food retail sector are: it has 
reached the sell-by date, product packing and product itself do not comply with required standards, and product returns [16].

Food waste caused by processing. According to the data from [17], approximately a quarter of food waste was generated by food manufacturing-179 kg/head. This was also confirmed by [18], their research indicated that food waste occurs at the upstream stages of value chains, and up to $12 \%$ for fruit, vegetables and potatoes were wasted from production to processing. [12] proposed that food waste generates mainly from five dimensions during the stage of food processing: (1) Internal requirements such as resource supply and raw material quality; (2) External requirements such as processing safety and quality requirements; (3) Intentional losses such as cleaning losses and samples for analysis; (4) Unintentional losses such as power blackouts and equipment defects; (5) Un-utilised by-products.

Food waste caused by logistics. In different stages of food value chain, logistics service providers assume the responsibility for mechanical product damages in transporting products from one stage to the other. These damages can cause different consequences, for example, products damage or contaminated in the transportation process that leads to rejection by the recipient [12]. In the case of raw or minimally processed foods, such as most tropical and subtropical fruits, a high fraction of food waste was contributed by insufficient cold chain utilisation [19]. In other circumstances, it is easy to cause impacts, compressions and abrasions on fresh products during the transportation process, if boxes are stacked incorrectly or if packages are used in improper size [20]. Other reasons for damaged packaging included vibrations during shipping process, a load-factor in outer packaging, overhang on pallets and that moisture weakened the courier paper [21].

Food waste caused by households. Most food waste is caused by downstream of the food value chain, especially in the interaction between retail, food service and the consumers as well as in consumer's home [22]. [4] defined the household food waste as "sources of food and drinks that are consumed within the home include retail and contributions from home-grown food and takeaways". According to the data from Food and Agriculture Organisations of the United Nations, less than $10 \%$ of the wastage occurs at the distribution level of Europe, but more than $30 \%$ of wastage are caused by consumers [1]. The potential reasons for food waste in households were listed in the following Table 2:

Table 2. Potential reasons for food waste generation in households

\begin{tabular}{|c|c|c|}
\hline \multicolumn{2}{|r|}{ Potential reasons for food waste generation } & \multirow{2}{*}{$\begin{array}{c}\text { Authors } \\
{[23]} \\
{[24]}\end{array}$} \\
\hline Planning & $\begin{array}{l}\text { 1. Lack of planning of food shopping and meals } \\
\text { 2. Inadequate communication between household } \\
\text { members }\end{array}$ & \\
\hline Shopping & $\begin{array}{l}\text { 1. Differences in taste } \\
\text { 2. Time constraints } \\
\text { 3.Oversized packaging }\end{array}$ & {$[24]$} \\
\hline Storing & 1. Improper and unsystematic storage practices & {$[25]$} \\
\hline Cooking & $\begin{array}{l}\text { 1. Preference of convenience food } \\
\text { 2. Over-preparation of food }\end{array}$ & {$[26][27]$} \\
\hline Eating & $\begin{array}{l}\text { 1. Unpredictable eating patterns } \\
\text { 2. Eating-out in restaurants } \\
\text { 3. Large plate sizes }\end{array}$ & {$[28]$} \\
\hline $\begin{array}{l}\text { Managing } \\
\text { leftovers }\end{array}$ & $\begin{array}{l}\text { 1. Wish for variety in meals } \\
\text { 2. Lack of knowledge about leftovers }\end{array}$ & [27] \\
\hline $\begin{array}{c}\text { Assessing } \\
\text { edibility }\end{array}$ & $\begin{array}{l}\text { 1. Confusion of date-labels } \\
\text { 2. Lack of knowledge about shelf-life food and how to } \\
\text { extend it }\end{array}$ & {$[28]$} \\
\hline $\begin{array}{c}\text { Disposal/ } \\
\text { Redistribution }\end{array}$ & 1. Lack of social acceptance of food sharing & $\begin{array}{l}29] \\
{[30]}\end{array}$ \\
\hline
\end{tabular}

A growing body of literature has investigated food-practices and routines in the context of food waste generation. Many causes of food waste have direct relationship with consumers, for example, lacking planning routines and cooking capabilities, misunderstanding of date-labelling, demanding high quality level of food that they want to buy, and avoiding potential risks [31,32]. [31] considered the effect of psycho-social factors, foodrelated routines, household perceived capabilities and socio-demographic on food waste, the results indicated that 
perceived behavioural control, routines related to shopping and reuse of leftovers are the main drivers of food waste, while planning routines contribute indirectly. [33] found that the size of plates has a positive correlation with the amount of food wasted, and larger plates induce people to eat more. [34] found that people who like to eat ready-made meals and restaurant take away will waste more edible food than others.

\subsection{Thematic analysis: food waste prevention strategies}

Appropriate food waste management is recognised as essential for sustainable development [35]. Reducing food waste throughout the food value chain should be considered as an effective solution to increase the income of food value chain members and to improve food security for low-income consumers [36].

Policy solutions. Regulatory approaches, such as laws and standards, mandatory management plans, restrictions or covenants that can help to achieve the target of reducing waste and induce consumers to form good behaviour. [37] proposed that one possible way to reduce food waste is to eliminate unnecessary food safety standards that lead to high food waste rates. [38] hold the same view that well-defined regulations seem to be a good weapon to fight with household food waste generation. Incentive-based regulatory approach such as economic incentives (fees, taxes and subsides) is another way that can be used to reduce food waste. [39] proposed that financial instruments have significant status in shifting consumer behaviours towards more sustainable food practices. A cross-country analysis has been conducted by [38] after collecting data from 44 countries with various income levels, their analysis results indicated that well-defined regulations, policies and strategies have a positive effect in mitigating household food waste generation. The most widespread tools used for reducing and preventing food waste are information campaigns [40], which have been implemented all over Europe to improve consumer's knowledge raise awareness about food waste prevention.

Packaging solutions. Packaging plays an important role in containing and protecting food as it moves through the value chain from producers to final consumers. Food waste can be reduced through the use of packaging that improves the lifespan of food, ventilation and temperature control [41]. In order to extend the lifespan of food, innovation and evolution in intelligent packaging with improved protection, communication, convenience, and containment are slowly entering the market [42]. Different technologies aimed at extending the shelf-life of food have been developed, such as multiple-layer barrier packaging, modified atmosphere packaging, oxygen scavengers and aseptic packaging. The most widespread used technology - oxygen scavengers, removing oxygen slows the degradation process and extends the shelf life of the food [41].

Date-labelling solutions. Date-labelling plays a vital role in informing both retailers and consumers about how long a food will remain edible, safe and of sufficient quality makes it a prime site for the identification of, intervention in, food waste [43]. As [40] proposed that two important reasons that can cause avoidable consumer food waste are: (1) lack of knowledge about the meanings of date labels; (2) confusion about the difference between expiry date and the date of minimum durability. In order to reduce confusion among consumers about expiry dates and the date of minimum durability, a big potential for reducing food waste lies in improving labels for prepacked food products, such as removing sell-by-date labels or reducing the indicating date of minimum durability used in some products [37]. Furthermore, advanced technology used in the labelling may help to reduce consumer food waste, such as Time-Temperature-Indicator device can help to identify low quality and potentially unsafe food [44].

Logistics solutions. [45] proposed that efficient information sharing among value chain partners and adaption of material flows, which have a positive effect on reducing food waste in the food value chain. [46] found that food waste can be reduced through taking shelf-life losses into consideration, if the result of standard cost parameters in poor product quality and large amounts of product waste were determined. Meanwhile, other researchers on food logistics have investigated the different areas of logistics that can help to reduce the food waste, for example, [47] conducted a simulation through using the information on the quality of products that provided by intelligent packaging, the results indicated that quality-controlled logistics can substantially reduce food waste. Further, after conducting 19 semi structured interviews and four site visits in the Swedish food value chains, [21] concluded that collaborative forecasting, division of lead time, low level of safety stock, packaging development, visualising damaged packaging, product group revisions, price reductions, make-to-order flows and measure of service levels, all these logistics activities can have a positive effect on food waste reduction. 
Reuse and redistribution solutions. [48] proposed different methods that can be used to reduce food waste. First, surplus food can be used to donate to non-profit organizations to help homeless people or used to sponsor specific organisations. Second, food companies can choose to distribute surplus products within their organisations or sales in the secondary market. Third, based on the type of products and the reason why the food waste generated, companies can remanufacture or repackage it. Finally, surplus food can be sold with promotions and discounts, or to sell to companies that produce animal feed or fertilizers.

Changing consumers' behaviours. A growing body of literature has investigated how to prevent food waste through changing consumers' behaviours. [27] proposed that careful planning of grocery shopping is an effective tool to prevent food waste. After collecting survey data from 1062 Danish respondents, [31] concluded that providing advice on how to deal with food-related activities at home through booklets or other such communication means, which have a positive effect on changing consumers' food waste behaviour. In addition, their research also indicates that participation in cooking courses or implementing household economics education campaigns are also effective in changing consumers' food waste behaviour. The possible food waste prevention measures related changing consumers' food waste behaviour were listed in the following Table 3:

Table 3. Possible food waste prevention measures

\begin{tabular}{|c|l|c|}
\hline \multicolumn{2}{|l|}{ Possible prevention measures } & Authors \\
\hline Planning & $\begin{array}{l}\text { 1. Using a shopping list } \\
\text { 2. Communication with household members... }\end{array}$ & {$[23][24]$} \\
\hline Shopping & 1. Increase shopping frequency & {$[24]$} \\
\hline Storing & $\begin{array}{l}\text { 1. Systematically storing and categorizing } \\
\text { 2. Freezing of food... }\end{array}$ & {$[25]$} \\
\hline Cooking & $\begin{array}{l}\text { 1. Greater frequency of cooking } \\
\text { 2. Better estimation of portion size... }\end{array}$ & {$[13][26]$} \\
\hline $\begin{array}{c}\text { Eating } \\
\text { Managing }\end{array}$ & 1. Household members with special diets & {$[28]$} \\
\hline $\begin{array}{c}\text { Assessing } \\
\text { edibility }\end{array}$ & 1. Reusing leftovers & {$[13][31]$} \\
\hline $\begin{array}{c}\text { Disposal/ } \\
\text { Redistribution }\end{array}$ & $\begin{array}{l}\text { 1. Giver food waste to pets } \\
\text { 2. Recycling and composting }\end{array}$ & {$[29][30]$} \\
\hline $\begin{array}{c}\text { Information } \text { and } \\
\text { knowledge } \\
\text { sharing }\end{array}$ & $\begin{array}{l}\text { 1. Implementing household economics education } \\
\text { campaigns } \\
\text { 2. Food waste related booklets... }\end{array}$ & {$[31]$} \\
\hline
\end{tabular}

\section{Research gaps and future directions}

The management of food waste has attracted the attention of researchers and practitioners over the last forty years and the focus has been on the causes of food waste, the reduction of the sources of the food waste from policy perspectives [38], packaging perspectives [41], date-labelling perspectives [40], logistics perspectives

[45], changing consumers' behaviours perspective, and reuse and redistribution perspectives [48]. The overview of the causes of food waste and food waste prevention strategies identified in this paper were demonstrated in Figure 1. In addition, the use of the advanced technologies that monitors production along the food value chain [49], the trends that using technologies to process the food waste [50], and the cost of food waste along the value chain have also been identified in the literature review process. Based on the review, the following research gaps have been identified and future research directions can be proposed: (1) Few researchers have explored how to forecast food waste in food value chains. Future research should investigate how to use holistic-adaptive forecasting methods to forecast food waste; (2) Little research considering how to reduce food waste from a logistics perspective involving producers/farmers. Therefore, future research should investigate how producers/farmers can participate in logistics solutions, involving efficient information sharing to reduce food waste; (3) Although different authors have proposed different solutions to reducing food waste in food value chains, these authors just investigated how to reduce food waste from one perspective. Future work is required that tests and assesses the effectiveness and impact of different food waste solutions combined together; (4) Little research exploring the impact of consumers' attitudes to reducing food waste in food value chains. Therefore, conducting semi structured interviews with different consumers on how to alter consumers' attitudes on 
suboptimal food can be as an important future research direction to reduce food waste; (5) Furthermore, little research has been conducted on how to reduce food waste through using value chain models. Future research should investigate new value chain coordination models, planning and replenishment strategies that can be used to reduce food waste.

\begin{tabular}{|c|c|}
\hline $\begin{array}{l}\text { Food over-production \& Surplus } \\
\text { 1. Food security } \\
\text { 2. Unexpected loss } \\
\text { 3. Production quality uncertainty }\end{array}$ & $\begin{array}{l}\qquad \text { Logistics } \\
\text { 1. Internal/External } \\
\text { requirements } \\
\text { 2. Intentional/Unintentional }\end{array}$ \\
\hline $\begin{array}{l}\text { Food processing } \\
\text { 1. Product damage/contamination } \\
\text { 3. Manipulation \& Storage } \\
\text { 4. Passed expiration dates }\end{array}$ & $\begin{array}{l}\text { 3. Incorrect topping } \\
\text { 4. Un-utilised by products } \\
\text { 5. Inappropriate time } \\
\text { management of operations }\end{array}$ \\
\hline & Food waste \\
\hline \multirow{2}{*}{$\begin{array}{l}\text { Changing Consumers' Behaviour } \\
\text { 1. Improve planning } \\
\text { 2. Increase shopping frequency } \\
\text { 3. Improve storage practices } \\
\text { 4. Improve eating patterns } \\
\text { 5. Reusing leftovers } \\
\text { 6. Recycling and composting } \\
\text { 7. Information and knowledge sharing }\end{array}$} & $\begin{array}{l}\text { Reuse \& Redistribution Solutions } \\
\text { 1. Donation to non-profit organisations } \\
\text { 2. Secondary market } \quad \text { 3. Remanufacturing } \\
\text { 4. Alternative uses (fertilizers, ...) }\end{array}$ \\
\hline & $\begin{array}{l}\text { Packaging Solutions } \\
\text { 1. Packaging development } 2 \text {. Visualising damaged } \\
\text { packaging 3. Improve life-span } \\
\text { 4. Ventilation and temperature control }\end{array}$ \\
\hline \multirow{2}{*}{$\begin{array}{l}\text { Logistics Solutions } \\
\text { 1. Information sharing } \\
\text { 2. Quality-controlled logistics } \\
\text { 3.Collaborative forecasting } \\
\text { 4. Division of lead time } \\
\text { 5. Low level of safety stocks } \\
\text { 6. Make-to-order flows } \\
\text { 7. Product group revisions }\end{array}$} & $\begin{array}{l}\text { Date-labelling Solutions } \\
\text { 1. Removing sell-by-date labels } \\
\text { 2. Using advanced technology in labelling }\end{array}$ \\
\hline & $\begin{array}{l}\qquad \text { Policy Solutions } \\
\text { 1. Well-defined regulations/policies } \\
\text { 2. Information campaigns } \\
\text { 3. Incentive-based regulatory approach }\end{array}$ \\
\hline
\end{tabular}

Fig. 1. The overview of the causes of food waste and food waste prevention strategies

\section{Discussion and conclusions}

In this study, we conducted a systematic literature review to identify the sources of food waste generation and food waste prevention strategies in food value chains. Through this process, we examined in total 147 journal papers. Main causes of food waste generation include food over-production and surplus, food waste caused by manufacturing, food waste caused by logistics and food waste caused by households. At the value chain level, some food waste can be controlled, such as food overproduction and food surplus can be reduced through communication and collaboration with value chain partners to increase the forecasting; food waste caused by manufacturing can also be reduced through production process optimization. However, some food waste caused by consumers is very difficult to control. Therefore, more empirical studies are needed to explore which methods are effective in reducing consumer-related food waste. As for the food waste prevention strategies, food waste can be reduced through developing appropriate policies, changing packaging and 
improving date-labelling, enhancing collaboration between food value chain partners, and reusing and redistributing of food waste. Although different researchers have conducted various studies in food waste prevention strategies, more research in this field is also necessary.

Being aware of the causes of food waste and food waste prevention strategies identified in the literature, food organisations can adjust their food waste prevention strategies according to their situations. In this context, food waste will either be tackled completely or offset to a controllable level by an organisation capability to adapt. Furthermore, it is easier to imagine that food waste will be controlled at a low level as a result of adopting different food prevention strategies in the food value chain. However, excessive food waste prevention strategies adopted in food value chains can erode revenue, for example, to adopt advanced technologies to process food waste, and lobby government officers for changing date-labelling policies. Likewise, if more effort is invested in adopting food waste prevention strategies, the daily operation of food organisations will be affected. Therefore, it is possible for food organisations or customers to choose the best food waste prevention strategies to adopt. Finally, further work is required to test and assess the effectiveness and economy of different food waste prevention strategies.

Acknowledgement. Authors of this publication acknowledge the contribution of the Project 691249, RUC-APS: Enhancing and implementing Knowledge based ICT solutions within high Risk and Uncertain Conditions for Agriculture Production Systems (www.ruc-aps.eu), funded by the European Union under their funding scheme H2020-MSCA-RISE-2015.

\section{References:}

1. FAO (2011) Global Food losses and Food Waste-Extent, Causes and Prevention. Gothenburg: Swedish Institute for Food and Biotechnology (SIK).

2. European Commission (2014) Food Waste and Its Impacts: European Week for Waste Reduction. Brussel: European Commission.

3. Grolleaud, M (2002) Post-harvest losses: discovering the full story. Overview of the phenomenon of losses during the post-harvest system. Rome: FAO.

4. Parfitt, J et al (2010) Food waste within food supply chains: quantification and potential for change to 2050. Phil. Trans. Biol. Sci. 365:3065-3081.

5. Teller, C et al (2018) Retail store operations and food waste. J. Clean. Prod. 185:981997.

6. Schanes, K. et al (2018) Food waste matters-A systematic review of household food waste practices and their policy implications. J. Clean. Prod. 182:978-991.

7. Denyer, D., Tranfield, T (2009) The Sage Handbook of Organisational Research Methods. London: Sage.

8. Tranfield, D., Denyer, D., Smart, P (2003) Towards a methodology for developing evidence-informed management knowledge by means of systematic review. Br. J. Manag. 14:207-222.

9. Durach, C.F. et al (2015) Antecedents and dimensions of supply chain robustness: a systematic literature review. Int. J. Phys. Distrib. Logist. Manag 45:118-137.

10. Datta, P (2017) Supply network resilience: a systematic literature review and future research. Int. J. Logist. Manag. 28:1387-1424. 
11. Rousseau, D.M., Manning, J., Denyer, D (2008) Evidence in management and organizational science: assembling the field,s full weight of scientific knowledge through syntheses. Acad. Manag. Ann. 2:475-515.

12. Raak, N et al (2017) Processing- and product-related causes for food waste and implications for the food supply chain. Waste Manag. 61:461-472.

13. Secondi, L., Principato, L., Laureti, T (2015) Household food waste behaviour in EU27 countries, A multilevel analysis. Food Pol. 56:25-40.

14. Mena, C et al (2011) The causes of food waste in the supplier-retailer interface: evidences from the UK and Spain. Res. Conserv. Recycl. 55: 648-658.

15. Ettouzani, Y. et al (2012) Examing retail on shelf availability: promotional impact and a call for research. Int. J. Phys. Distrib. Logist. Manag. 42:213-243.

16. Garrone, P et al (2014) Surplus food recovery and donation in Italy: the upstream process. British Food J. 116: 1460-1477.

17. European Commission (2011) EU Guidnace to the Commission Regulation (EC) No 450/2009 of May 2009 on Active and Intelligent Materials and Articles Intended to Come into Contact with food. Version 1.0. Belgium: Health and Consumers Directorate-General of European Commisssion.

18. Redlingshofer, B et al (2017) Quantifying food loss during primary production and processing in France. J. Clean. Prod. 164:703-714.

19. Jedermann, R et al (2014a) Reducing food losses by intelligent food logistics. Philosophical Transactions of The Royal Society A 372: 20130302.

20. Li, Z., Thomas, C (2014) Quantitative evaluation of mechanical damage to fresh fruits. Trends Food Sci. Technol. 35:138-150.

21. Liljestrand, K (2017) Logistics solutions for reducing food waste. Int. J. Phys. Distrib. Logist. Manag. 47:318-339.

22. Gobel, C et al (2015) Cutting food waste through cooperation along the food supply chain. Sustainability 7:1429-1445.

23. Farr-Wharton, $\mathrm{G}$ et al (2014) Identifying factors that promote consumer behaviours causing expired domestic food waste. J. Consum. Behav. 13:393-402.

24. Jorissen, J et al (2015) Food waste generation at household level: results of a survey among employees of two European research centers in Italy and Germany. Sustainability 7:2695-2715.

25. Martindale, W (2014) Using consumer surveys to determine food sustainability. Br. Food J. 116:1194-1204.

26. Graham-Rowe, E et al (2014) Identifying motivations and barriers to minimising household food waste. Res. Conserv. Recycl. 84:15-23.

27. Secondi, L et al (2015) Household food waste behaviour in EU-27 countries: a multilevel analysis. Food Pol. 56:25-40.

28. Parizeau, K et al (2015) Household-level dynamics of food waste production and related beliefs, attitudes and behaviours in Guelph, Ontario. Waste Manag. 35:207217.

29. Wenlock, R et al (1980) Household food wastage in Britain. Br. J. Nutri. 43:53-70.

30. Tucker, C., Farrelly, T (2015) Household food waste: the implications of consumer choice in food from purchase to disposal. Local Envir. 21:682-706.

31. Stacu, V et al (2016) Determinants of consumer food waste behaviour: two routest o food waste. Appetite 96:7-17.

32. Waston, M., Meah, A (2013) Food waste and safety: Negotiating conflicting social anxieties into the practices of domestic provisioning. Socio. Rev. 60:102-120.

33. Wansink, B., Van Ittersum, K (2013) Portion size me: plate-size induced consumption norms and win-win solutions for inducing food intake and waste. J. Exp. Psychol. Appl. 19:320-332.

34. Mallinson, L.J. et al (2016) Attitudes and behaviour towards convenience food and food waste in the United Kingdom. Appetite 103:17-28. 
35. UNEP (2011) Decoupling Natural Resource Use and Environmental Impacts from Economic Growth. Paris: United Nations Evvironment Programme.

36. Rezaei, M., Liu, B (2017) Food loss and waste in the food supply chain [Online]. Rome: FAO. Available at: http://www.fao.org/save-food/news-andmultimedia/news/newsdetails/en/c/1026569/ [Accessed: 19 May 2018].

37. Schanes, K et al (2016) Low carbon lifestyles: a framework to structure consumption strategies and options to reduce carbon footprints. J. Clean. Prod. 139:1033-1043.

38. Chalak, A et al (2016) The global economic and regulatory determinants of household food waste generation: A cross-country analysis. Waste Manag. 48:418422.

39. Reisch, L.A. et al (2013) Sustainable food consumption: An overview of contemporary issues and policies. Sustainability: Sci. Practice and Pol. 9: 7-25.

40. Priefer, $\mathrm{C}$ et al (2016) Food waste prevention in Europe-A cause-driven approach to identify the most relevant leverage points for action. Res. Conserv. Recycl. 109:155165.

41. Verghese, $\mathrm{K}$ et al (2015) Packaging,s role in minimizing food loss and waste across the supply chain. Packag. Technol. Sci. 28:603-620.

42. Vanderroost, $M$ et al (2014) Intelligent food packaging: The next generation. Trends Food Sci. Technol. 39:47-62.

43. Milne, R (2013) Arbiters of waste: date labels, the consumer and knowing good, safe food. Sociol. Rev. 60:84-101.

44. Newsome, R et al (2014) Applications and perceptions of date labelling of food. Compr. Rev. Food Sci. Food saf. 13:745-769.

45. Kaipia, R et al (2013) Creating sustainable fresh food supply chains through waste reduction. Int. J. Phy. Distrib. Logist. Manag. 43:262-276.

46. Rijpkema, W et al (2014) Effective sourcing strategies for perishable product supply chains. Int. J. Phys. Distrib. Logist. Manag. 44:494-510.

47. Heising, J.K. et al (2017) Options for reducing food waste by quality-controlled logistics using intelligent packaging along the supply chain. Food Additives \& Contaminants: Part A 34:1672-1680.

48. Garrone, P et al. (2016) Reducing food waste in food manufacturing companies. J. Clean. Prod. 137:1076-1085.

49. Muriana, C (2017) A focus on the state of the art of food waste/losses issue and suggestions for future research. Waste Manag. 68: 557-570.

50. Papargyropoulou, E et al (2014) The food waste hierarchy as a framework for the management of food surplus and food waste. J. Clean. Prod. 76: 106115. 